\title{
A Review in Developing a High Rise Building Construction Safety and Health Risk Model
}

\author{
Afzan Binti Ahmad Zaini, Intan Rohani Endut \\ and Nurzawani Binti Md Sofwan
}

\begin{abstract}
The construction industry is starting to gain momentum as Malaysia is becoming a fully industrialised country by the year 2020. Due to the complexity and dynamic nature of a construction project, specifically on high rise building, various hazards and risks are already in place at any stage of a project lifecycle. Safety and health risk assessment is the core of any safety practices in any industry. Risk at the construction site should be assessed prior to manage or mitigate it. Therefore, this paper intends to recognize the theoretical aspects of the likelihood and severity of the hazards in the high rise building construction project and to recognize a theoretical aspects in formulating a high rise building construction safety and health risk model. The methodology employed $\mathrm{f}$ or this paper includes the secondary data collection from journals, articles and government statistics. The successful investigations will lead to the development of safety and health risk model in the construction industry particularly for high rise building construction. This model has prospect to be commercialized through the intellectual property (IP). The health and safety risk model will promote safety climate in the construction site and hence, enhancing the performance of human capital.
\end{abstract}

Keywords Hazards - Risk - Safety and health risk model • High rise building construction

\footnotetext{
A.B.A. Zaini $(\bowtie)$

Department of Quantity Surveying, Faculty of Architecture Planning and Surveying, Universiti Teknologi MARA, Kota Samarahan, Sarawak, Malaysia

e-mail: afzanahmadzaini@gmail.com

I.R. Endut

Faculty of Civil Engineering, Universiti Teknologi MARA, Shah Alam, Malaysia

N.B.M. Sofwan

Faculty of Health Science, Universiti Teknologi MARA, Kota Samarahan,

Sarawak, Malaysia

(C) Springer Science+Business Media Singapore 2015

R. Hassan et al. (eds.), InCIEC 2014, DOI 10.1007/978-981-287-290-6_22
} 